\title{
Cell-balancing currents in parallel strings of a battery system
}

\author{
Matthieu Dubarry ${ }^{\mathrm{a} *}$, Arnaud Devie ${ }^{\mathrm{a}}$ and Bor Yann Liaw ${ }^{\mathrm{a}}$ \\ ${ }^{a}$ Hawaii Natural Energy Institute, SOEST, University of Hawaii at Manoa \\ 1680 East-West Road, POST 109, Honolulu, HI 96822, USA \\ matthieu@hawaii.edu, adevie@hawaii.edu, bliaw@hawaii.edu
}

\begin{abstract}
Lithium-ion batteries are attractive for vehicle electrification or grid modernization applications. In these applications, battery packs are required to have multiple-cell configurations and battery management system to operate properly and safely. Here, a useful equivalent circuit model was developed to simulate the spontaneous transient balancing currents among parallel strings in a battery system. The simulation results were validated with experimental data to illustrate the accuracy and validity of the model predictions. Understanding the transient behavior of such cell and string balancing in a parallel circuit configuration is very important to assess the impacts of current fluctuation and cell variability on a battery system's performance, regarding durability, reliability, safety, abuse tolerance and failure prevention, including possible short circuit or open circuit conditions. Additional features and advantages, including the ability to assessing impacts on the performance of the string assemblies from string swapping or cell/module replacement in the strings, could be realized to aid battery management, maintenance and repair.
\end{abstract}

\section{Keywords}

Li-ion batteries and packs; parallel string configurations; battery swapping; cell balancing; battery management

*Corresponding author: matthieu@hawaii.edu. 


\section{INTRODUCTION}

Reliability and safety are important and timely issues for lithium-ion batteries [1] that shall be addressed by stakeholders in all sectors where large battery packs are required to meet highenergy and high-power demands. Particularly, if multiple-cell configurations have parallel strings, the transient current distributions and variations among the strings are of great concerns in battery management systems (BMS) to perform cell balancing and protection in the battery module or system levels. These transient current distributions and variations may introduce some long-lasting effects on battery performance, which are not easy to detect in a short time frame. To address these issues, a high-fidelity equivalent circuit model could be used as a powerful tool to simulate these transient current distributions and variations to help engineers deal with the reliability and safety issues.

Here, we tested a group of commercial 18650 cells as a platform to develop useful techniques to understand and to model the transient behavior of cells in parallel configurations, and to perform validation. These lithium-ion cells are made of graphite negative electrode (NE) and a blend of $\left\{\mathrm{Li}_{\mathrm{x}} \mathrm{Mn}_{1 / 3} \mathrm{Ni}_{1 / 3} \mathrm{Co}_{1 / 3} \mathrm{O}_{2}(\mathrm{NMC})+\mathrm{Li}_{\mathrm{x}} \mathrm{Mn}_{2} \mathrm{O}_{4}(\mathrm{LMO})\right\}$ mixture as the active material in the composite positive electrodes (c-PE). These cells were made by a brand name manufacturer. The cell chemistry has been studied in our laboratory in a series of investigations on subjects from cell variability [2], cycle aging and degradation mechanism [3], capacity fading in temperature excursions [4], a peculiar capacity fade phenomenon in the c-PE associated with overdischarge [5], to the methodology in determining state-of-charge (SOC) and state-of-health (SOH) of the cells and multi-cell strings $[6,7]$. Here, we discussed the transient aspects of parallel string configurations and the string balancing issues. 
Prior studies on parallel configurations and their impacts on performance with lithium-ion batteries are limited in numbers and scopes. Most of the studies focused on circuit topology and electrical balancing issues rather than on the electrochemical behavior of the system (e.g. [813]). To the best of our knowledge, only a few of the impacts of cell performance with parallel multi-cell configurations have been published with electrochemical characterizations [14-27]. In Ref. [14], the experiments were conducted to investigate a set of graphite (Gr) $\| \mathrm{LiFePO}_{4}$ cells with small temperature gradients introduced; however, the time for the cells to reach balance and transient fluctuations of the current in the circuit were not discussed. In Ref. [15], electrode plates stacked in parallel in a cell were studied to understand the static distribution of current among the plates. The transient balancing current distribution during the initial period of polarization was not discussed. Only a few studies provided electrochemical data for both voltage and current evolutions during constant current discharging of commercial cells [17, 20, $21,25]$. These studies showed the results of current distributions among strings via modeling or experimentation but did not explain the mechanism that drives the initial balancing current distribution in the parallel configurations.

Understanding the transient behavior of the cells in parallel is of great interest for practical applications in vehicle or energy storage systems and some key issues need to be addressed with sufficient detail in understanding. The best introduction to these key issues can be found in Ref. [28]. Understanding these issues is crucial to assuring durability, reliability and safety of the battery systems. Such information is critical to the strategy of protecting cells from abuses by the users and malfunctions in the battery pack. Possible solutions may include building in redundancies to withstand negligence and abuse and to manage reliability issues beyond the cell level, handling failure modes (in either open or short circuit conditions) by proper detections, 
and accommodating string re-configurations (e.g. changing defective strings with new ones) in system maintenance and repair; just to name a few.

A prerequisite to address these issues is sufficient knowledge of cell variability, i.e. cell-tocell variations in various cell characteristics [2, 24, 29-31], and the ability to accommodate them $[29,32]$. In this work, this aspect is accomplished by using an equivalent circuit model (ECM) modified to simulate battery strings in parallel. This model was dubbed kaulike, the Hawaiian word of "evenly balanced," to emphasize its unique capability in the simulation of parallel strings in a battery pack.

\section{EXPERIMENTAL}

A batch of 1.9 Ah 18650 lithium-ion cells comprising graphite $\mathrm{NE}$ and $\left\{\mathrm{Li}_{\mathrm{x}} \mathrm{Mn}_{1 / 3} \mathrm{Ni}_{1 / 3} \mathrm{Co}_{1 / 3} \mathrm{O}_{2}\right.$ $\left.+\mathrm{Li}_{\mathrm{x}} \mathrm{Mn}_{2} \mathrm{O}_{4}\right\}(\mathrm{NMC}+\mathrm{LMO}) \mathrm{c}-\mathrm{PE}$ was used as test samples for illustration. One of the cells was subjected to a reference performance test (RPT) consisting of $\mathrm{C} / 25, \mathrm{C} / 5, \mathrm{C} / 2,1 \mathrm{C}, 2 \mathrm{C}$, and $2.5 \mathrm{C}$ cycles at $25^{\circ} \mathrm{C}$ over an extended voltage range from $2.300 \mathrm{~V}$ to $4.250 \mathrm{~V}$ to characterize the cells' performance characteristics. The results were used to extract parameters for the ECM [32, 33]. The same methodology was used to build an ECM from an aged cell for which the RPT data was taken from Ref. [3].

The 18650 cells were placed in cell holders [34] made by Arbin Instruments (College Station, TX) to handle high current testing. These cell holders offer low resistance (on the order of a few $\mathrm{m} \Omega$ ) to maintain reliable contact, provide ability to handle high power testing, and introduce minimum impact on test results from external resistive influences. These cell holders have a lever that can be used as a mechanical switch to close the circuit quickly and safely. In order to record precise current passing through each string without artifacts from the influences of additional resistance and voltage perturbation possibly induced by the introduction of DC 
shunt resistors, CTH Hall-effect DC transducers [35] were used in the measurements, which have $0.5 \%$ precision over a current range of $\pm 25 \mathrm{~A}$.

Three tests were performed with cells at different SOCs. Cells were pre-conditioned using an Arbin HVBT-5560 58-channel 5V/5A tester and cycled at C/2 rate to specified cutoff voltages at $3.050 \mathrm{~V}, 3.350 \mathrm{~V}$, or $4.200 \mathrm{~V}$, respectively; followed by a $24-\mathrm{h}$ rest prior to commencing parallel-string tests. The parallel-string tests with $1 \mathrm{~S} 2 \mathrm{P}, 1 \mathrm{~S} 3 \mathrm{P}$, and 2S2P configurations were conducted in a temperature-controlled environment. In the tests, a 6-h rest between consecutive test regimes was typically exercised to allow cells and strings recuperate from polarization. Each test was launched with only one string connected to the ARBIN tester first, while the other strings were hot connected $30 \mathrm{~s}$ after commencing the test on the first string in order to record the voltages of the cells in the strings before and after the hot connection to the test. Hot connections of the strings could be enabled safely by using the levers on the cell holders. Auxiliary voltage monitoring channels were used to record the voltage of every cell in the circuit and the current sensing output of the Hall-effect transducer in each string.

\section{RESULTS}

\subsection{Equivalent circuit model}

Figure 1 presents a series of cell voltage $\left(V_{\text {cell }}\right)$ vs. SOC $\left(V_{\text {cell }}=f(\mathrm{SOC})\right)$ curves determined from the nominal cell with rates from $\mathrm{C} / 25$ to $2 \mathrm{C}$ in the charge and discharge regimes. In addition, a pseudo open circuit voltage vs. SOC $(p s-O C V=f(S O C))$ curve was derived from the charge and discharge $\left(V_{\text {cell }}=f(Q)\right)$ curves at $\mathrm{C} / 25$ with an SOC scaling process in which the total charge released in each regime was used as the denominator for SOC calculation. In this figure, an illustration of cell balancing with two cells in parallel connection is presented. Supposing that 
these two cells were at different SOCs, say $1.3 \%$ and $91.0 \%$, respectively (i.e. their OCVs were at $3.200 \mathrm{~V}$ and $4.100 \mathrm{~V}$ ); according to Kirchhoff's laws, upon connecting the cells in parallel the voltage of the two cells must be the same. Therefore, a cell balancing current would occur to force the cells to reach the same voltage by transferring charge from one that has a higher initial voltage to the other until their voltages become the same. To illustrate how the voltage and the induced current ( $\mathrm{C}$ rate) were determined, a horizontal line and two arrows are used to show how the balancing of voltage and current occurs. Since the balancing current must be the same (but with opposite signs) between the two cells, the position of the horizontal line was settled (i.e. the voltage of the parallel configuration) at about $3.700 \mathrm{~V}$, when a "common absolute $\mathrm{C}$ rate" was found to permit the polarization in each cell to reach the same voltage, as the arrows exemplified. In this example, to accommodate the $90 \%$ SOC difference, the balancing act should start at about $2 \mathrm{C}$.

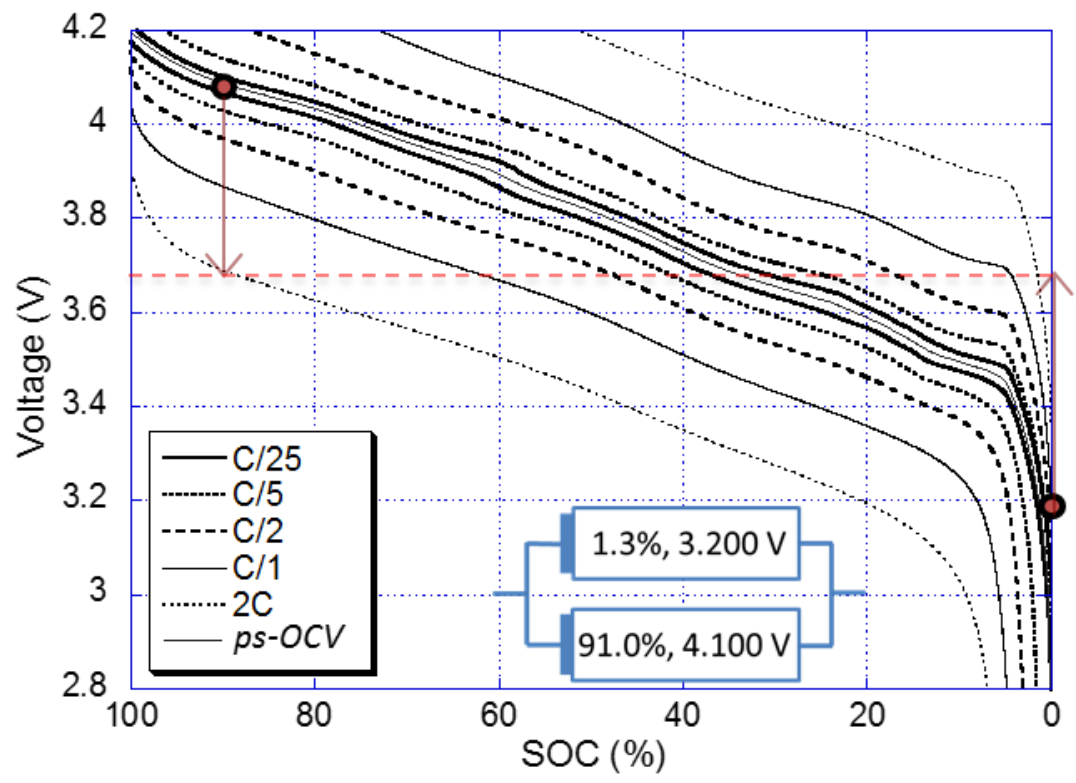

Figure 1: Cell voltage $v s$. SOC curves determined by experiments for a nominal cell and a schematic illustration of a hypothetical 1S2P configuration in which how the rate of the 
balancing current and the final voltage of the assembly determined for the two cells at $91.0 \%$ and $1.3 \%$ SOC (4.100 V vs. $3.200 \mathrm{~V})$, respectively, initially before being connected in parallel.

To illustrate the principles of the ECM used in this work, we shall begin with explanations on what the essence of such a model is. Figure 2 shows a schematic to explain how this ECM is constructed and how it works. Similar work has been described in detail in Refs. [32, 33]. The ECM comprises a battery that serves as voltage or current source, an ohmic resistive element that represents the battery's overall bulk conductive resistance in contact with the external circuit, and a RC circuit that represents the battery's overall interfacial and reactive resistance and capacitance associated with the electrochemical reactions. As an electron source, the cell chemistry exhibits a characteristic $p s-O C V=f(S O C)$ curve, delineating the driving force (electrochemical potential) for conducting external work on the load based on the thermodynamic potential difference between the positive and negative electrodes. The two resistive elements and the capacitance in the ECM depict the cell impedance governed by the internal kinetic constraints. The interplay of the thermodynamic potential in driving force and the kinetic constraints determines the polarization characteristics of the cell, as illustrated by these rate-dependent discharge curves in the figure simulated from the ECM. The parameters for these circuit elements in the ECM are determined by the RPTs in the laboratory, which could be replicated in a BMS with proper monitoring protocols and parameter derivations:

- In the figure, $V_{O C}$ corresponds to that of the $p s-O C V=f(S O C)$ curve for given cell chemistry. With a diagnostic model, as described in Ref. [36], and the methods to determine SOC and $\mathrm{SOH}$ in a pack, as described in Refs. $[6,7]$, the $p s-O C V=f(S O C)$ curve could be updated timely for in-line analyses and prognoses, as the system ages. 
- $\mathrm{R}_{1}$ can be obtained from the initial IR drops at different rates. The value can be monitored inline, as part of the diagnostic routine.

- $\mathrm{R}_{2}$ can be determined at each SOC from the observed polarization resistance minus $\mathrm{R}_{1}$.

The capacitance $C$ is the only parameter in the ECM whose attribute has been neglected in the earlier studies, because the DC behavior in the charge discharge regimes was the main focus and transient response was deemphasized. In this work, the capacitance needs to be considered since it will have a significant impact on the accuracy of the transient current profiles where the impedance of the entire cell configuration matters. This need of using the capacitance in the simulation justifies the choice of the ECM approach rather than simple voltage interpolations. Since there was no desire to perform EIS measurements on the cells, as such measurements might be impractical in real-life systems, an alternative solution has to be considered here. In practical applications, capacitance values with a time constant on the order of $20 \mathrm{~s}$ would be useful, according to those suggested in the literature [37]. In this work, a $20 \mathrm{~s}$ time constant was used and, since the cells were placed at open circuit prior to the tests, the capacitance was considered to be at an initial non-polarized state. The voltage of the battery assembly was calculated using the equations provided in Ref. [37]. With this approach the transient voltage fluctuations from the OCV can be calculated at any rate for a certain SOC. 


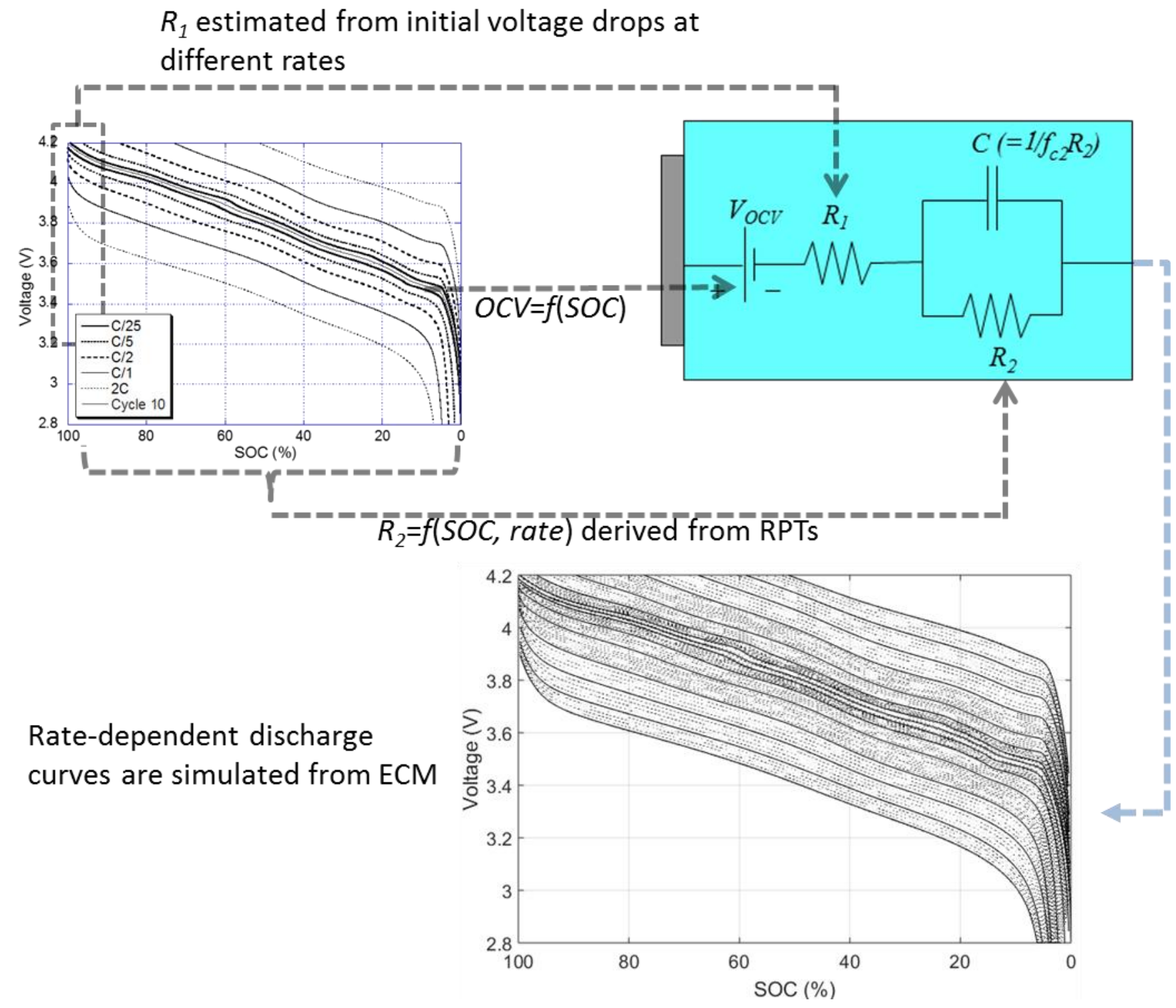

Figure 2: Schematic illustrating the ECM approach used in this work and how parameters and the $V_{\text {cell }}=f(\mathrm{SOC})$ curves at different rates were derived.

With the understanding of the single cell ECM explained above in Figure 2, we should look into parallel configurations and how to apply the ECMs to these multi-cell configurations to help understanding their characteristics. As we step into this territory, we soon realize that, as the number of cells in the string and the number of strings in the parallel configuration increase, the 
system could become quite complicated, in part, because of the cell-to-cell variations [2, 24, 29-

31]. The types of cell variability include variations in the active material content, rate capability, or cell impedance $[2,29,30]$. The cell impedance could be related to not only the electrical responses of electrochemical origins but also the ohmic contact at each node in the circuit. The impedance is also composition- and SOC-dependent; therefore, any intrinsic variations in the composition of the active material or the cell balance could attribute to differences in impedance and accordingly the response time in the circuit. Furthermore, the impedance in the discharge regime could be different from that in the charge [38, 39], and voltage hysteresis due to mechanical stress and strains created by charge and discharge cycling is also possible $[40,41]$. All of the above shall affect the $p s-O C V=f(S O C)$ relationship and the impedance responses during the transient states.

To simulate the cell balancing with respect to parallel configurations among cells and strings, a model intended to simulate the transient behavior of the system must be able to accommodate the complexity of cell variability in impedance and trace the voltage responses of the cell at any rate and SOC with sufficient temporal resolution. The model should be efficient in computation so the calculations with multiple-cell configurations and topologies in circuitry are feasible. The ECM approach [29, 32, 33, 42] in this work should be demonstrated adequate for this purpose.

\subsection{Modeling cells in parallel}

\subsubsection{Balancing current calculation}

Using the ECM described above and starting with a simple scenario of a 1S2P configuration, the derivation of the balancing current is illustrated here. At first, the ECM was used to calculate the $V_{\text {cell }}=f(S O C)$ curves at various $\mathrm{C}$ rates for both cells. For rates that were not measured experimentally, interpolations were used to derive those curves. These $V_{\text {cell }}=f(S O C)$ curves 
emulating the cell voltage as a function of $\mathrm{C}$ rate and SOC are shown in Figure 3(a). To illustrate how cell balances in the 1S2P configuration, the same SOCs as presented in Figure 1 were used here for the illustration, i.e. $1.3 \%$ and $91.0 \%$, as shown by the red and blue lines in Figure 3(a), respectively. The polarization behavior of each cell is expressed by the voltage variations as a function of $\mathrm{C}$ rate (i.e. the $V_{\text {cell }}=f($ rate $)$ curve) extracted from the charge/discharge curves in Figure 3(a) at the respective SOC, as shown in Figure 3(b). These curves are not necessarily linear but assumed to be monotonous. According to Kirchhoff's laws, the voltage of the cells should be equal to each other and the sum of the current equals to that of the assembly. Applying these principles, the transient voltage and current could be obtained from the $V_{\text {cell }}=f($ rate $)$ curves either by scanning rates for each cell to find a matched voltage or by scanning voltages to find where the sum of the rates equals the assembly rate. We chose the latter because it is easier to apply this approach in the ECM computation than the former. Figure 3(c) presents a plot in which the $V_{\text {cell }}=f($ rate $)$ curve of cell 1 at SOC of $91.0 \%$ is shown with a second $\mathrm{x}$-axis on the top to express the corresponding rate in cell 2. Additionally, a second y-axis is also presents on the right to illustrate the sum of the rates in both cells, i.e. the assembly rate. This plot shows the rates in both cells as well as the assembly voltage and its commending rate. The gray dot and dashed lines represent the condition where the overall assembly rate is zero (i.e. assembly is open-circuit). Under this scenario, cell 1 discharges at a $2 \mathrm{C}$ rate (i.e. $-2 \mathrm{C}$ per our convention) while cell 2 charges at a $2 \mathrm{C}$ rate (i.e. $+2 \mathrm{C}$ per our convention), initially. The assembly and the two cells all reach the same voltage, $3.684 \mathrm{~V}$. A second scenario is depicted by a green dot and dashed lines where the assembly discharges at a $2 \mathrm{C}$ rate overall (i.e. $-2 \mathrm{C}$ per our convention) Under this discharge scenario, cell 1 discharges at a $3 \mathrm{C}$ rate whereas cell 2 charges at a $1 \mathrm{C}$ rate, initially. Accordingly, the assembly voltage is 3.448V, initially. Therefore, Figure 3(c) allow us to examine and understand the transient behavior of this $1 \mathrm{~S} 2 \mathrm{P}$ configuration. For instance, as the 
terminal voltage varies, the internal balancing current in the assembly and each cell can be determined. It should be noted that, due to the asymmetric nature of the kinetics in each cell, as shown in the $p s-O C V=f(\mathrm{SOC})$ curve, characteristics of the cell balance may not follow the linear relationship as depicted in the figure. This aspect may affect to some extent the accuracy and precision of the ECM prediction. The asymmetric nature can be further examined; for example, the assembly voltage $(3.684 \mathrm{~V})$ predicted from current balancing where the assembly rate is zero is different from the average of the OCVs of the two cells, $3.650 \mathrm{~V}$. 

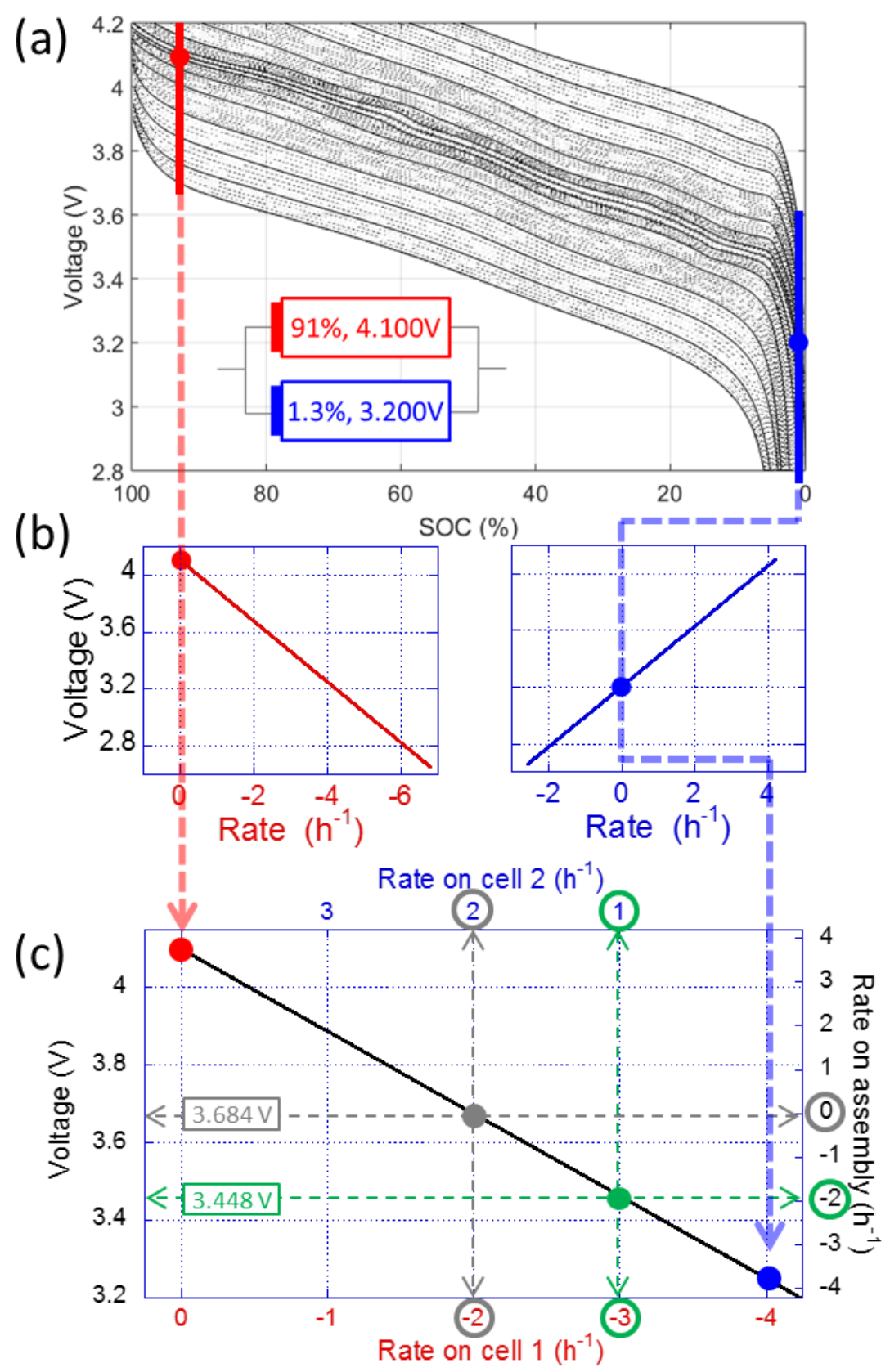

Figure 3: Schematic illustrating the application of (a) $V_{\text {cell }}=f(\mathrm{SOC})$ curves in the determination (b) of the single cells polarization curves and (c) of the rate of the balancing current and the final voltage of the cell assembly in the 1S2P configuration. 
The generalization of applying this computation approach to any $n \mathrm{~S} m \mathrm{P}$ configuration is schematically shown in Figure 4. The initial balancing current and voltage of an $n \mathrm{~S} 2 \mathrm{P}$ assembly (dotted box) could be determined by a similar approach using $V_{\text {string }}=f($ rate $)$ curves, each being the sum of the $V_{\text {cell }}=f($ rate $)$ curves of the cells in the string. As the number of strings in parallel ( $m$ in an $n \mathrm{~S} m \mathrm{P}$ configuration) increases, the complexity of determining the balancing current and voltage in an assembly increases. However, the same approach remains valid, as shown in Figure 4. The process starts with choosing a reference $V_{\text {string }}=f($ rate $)$ curve among the strings in the assembly. Once the reference is selected, the rate in other strings to follow the voltage of this reference string at a given rate can be calculated. Similar to the $1 \mathrm{~S} 2 \mathrm{P}$ and $n \mathrm{~S} 2 \mathrm{P}$ cases, rates in any $n \mathrm{~S} m \mathrm{P}$ assembly can be summed and compared to the sum of the voltages of the cells in the reference string so that the rate on every string can be determined if the assembly voltage or the internal balancing rate is known. 


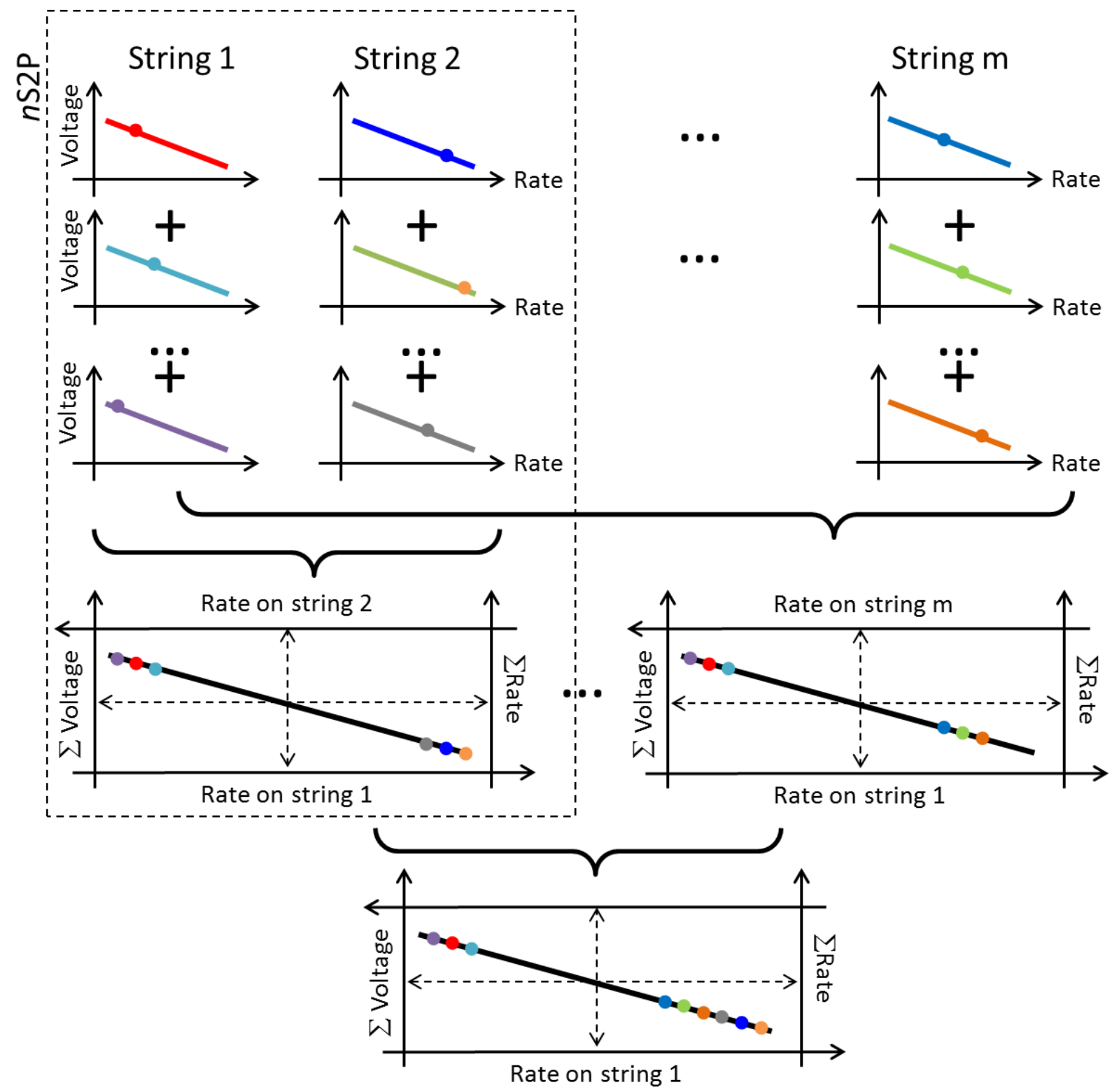

Figure 4: An illustration of the determination of the rate of balancing current and the final voltage of the assembly in (a) an $n \mathrm{~S} 2 \mathrm{P}$ configuration and (b) for an $n \mathrm{~S} 2 \mathrm{P}$ configuration (dotted box) and an $n \mathrm{~S} m \mathrm{P}$ configuration.

With these examples presented, it appears feasible to apply this approach and ECM to derive the balancing rate and the final state for a variety of $n \mathrm{~S} m \mathrm{P}$ configurations. However, before stepping into any additional discussion, we should note that the technique we used so far only 
considered the initial balancing rate, without any temporal resolution. To enable a time-series dynamic simulation with net balancing current perturbations, we would need time-dependent solutions.

\subsubsection{Time steps and computation time}

The methodology described in the previous section allows determining the initial balancing current and voltage when the strings are connected together. After the passing of balancing currents, the SOC on all the cells within the assembly changed and the calculation needs to be repeated until a steady state, equilibrium, or a cutoff condition (depending on if the net current should be zero or a finite value) are reached. Here we begin to focus on how to determine balancing current with temporal resolution that provides sufficient precision, accuracy, without exhausting computation resources. The time step between two iterations is a critical factor for computation resource requirements. In this approach, for a multiple-string configuration, a significant amount of rate scanning is involved in each iteration step. To minimize the computation resources, while ensuring sufficient precision and accuracy, a variable time step strategy was implemented in the simulation procedure. The time step was based on an interval that lasts not to exceed $0.1 \%$ string rated capacity at the maximum rate in any of the strings. For example, a time step of $3.6 \mathrm{~s}$ should be used in the iterations if the maximum current in any of the strings is $1 \mathrm{C}$ (i.e. the string is being discharged or charged in 3,600 s); yet, it is increased to $90 \mathrm{~s}$ when $\mathrm{C} / 25$ is engaged toward equilibrium. For example, the balancing current evolution toward equilibrium for a 1S6P assembly with a constant time step of $3.6 \mathrm{~s}$ would take about 1,000 s of computation time using a desktop computer with an Intel ${ }^{\circledR}$ Core $^{\mathrm{TM}}$ i7 chip @ 2.80 $\mathrm{GHz}$ and $8 \mathrm{~GB}$ of memory operated in Windows 10 . In contrast, it took $30 \mathrm{~s}$ using a variable time step in the implemented strategy to achieve similar precision and accuracy. 


\subsection{Validation}

To validate the precision and accuracy of the ECM simulations, three multi-cell assemblies were used in the experiments with increasing complexity: 1S2P, 1S3P and 2S2P. We believe the results should validate the presumption that this methodology should be applicable to any $n \mathrm{~S} m \mathrm{P}$ assembly. To validate extremes in the design of experiments and to achieve the maximum contrast in the magnitudes and variations of the balancing current, one of the strings was set to an almost fully discharged state intentionally, and another at least more than half charged. To ensure safety, in the 2S2P experiment, the strings were assembled with cells of similar SOCs (i.e. with minimal cell variability in SOC within a string).

Figure 5 presents a series of results of the experimental testing on (a) 1S2P, (b) 1S3P, and (c) 2S2P configurations, each with a comparison between the experimental data (in gray) and simulations (in black). For the $1 \mathrm{~S} 2 \mathrm{P}$ experiment, one cell was set to $5.0 \% \mathrm{SOC}$ and the other to $65.0 \%$ SOC. For the 1S3P experiment, a third cell at $35.0 \%$ SOC was added. The solid lines referred to the left scale are the string voltage profiles, and the dotted lines referred to the right scale are the current evolutions. Overall, the simulation results for the voltage and current evolutions are in good agreement with the experimental data. In Figure 5(a), the voltage dropped to $3.705 \mathrm{~V}$ first within $6 \mathrm{~min}$, bounced to about $3.712 \mathrm{~V}$ in $15 \mathrm{~m}$, then decayed to $3.691 \mathrm{~V}$ about one and half hours later. The simulation results appear really accurate for the second and third stage but a few $\mathrm{mV}$ off in the first one. The evolutions of the current profiles in the strings also show great precision. In both strings, the current quickly fell below $1 \mathrm{C}$ and took about three hours to reach a stabilized state. With such success, it is still worth noting that the ECM in this work primarily focuses on electrochemical behavior of parallel strings, so it might be too simple to handle high frequency responses (e.g. time steps less than $1 \mathrm{~s}$ ) during the initial polarization where fluctuations in the string voltage and current should occur at a significant and complicated 
level. For instance, in the 1S2P experiment, the data showed that an initial current of $1.55 \mathrm{C}$ was measured, whereas $1.90 \mathrm{C}$ was predicted. However, the simulated current was under $1.55 \mathrm{C}$ in less than $5 \mathrm{~s}$ and became more consistent with the experimental results. In the 1S3P case, precision and accuracy of the simulation were better, with currents simulated at $1.80 \mathrm{C}$ and $-1.79 \mathrm{C}$ for the highest and lowest voltage strings, in contrast to $1.69 \mathrm{C}$ and $-1.84 \mathrm{C}$ experimentally. The third string in the 1S3P assembly was initially at a potential close to the one at equilibrium. Thus, the string did not involve much in balancing, merely with current fluctuations ranging from $-0.03 \mathrm{C}$ to $0.03 \mathrm{C}$ throughout the experiment. The inset in Figure 5(b) shows an enlarged view of this current evolution in comparison with the simulation. The accuracy issue was still there for the first six minutes, but the simulation was sufficiently accurate for the rest of the experiment. Despite the small initial discrepancy in simulation, the model grasped the evolution of the cell balance well and predicted the alternating charge and discharge periods. 

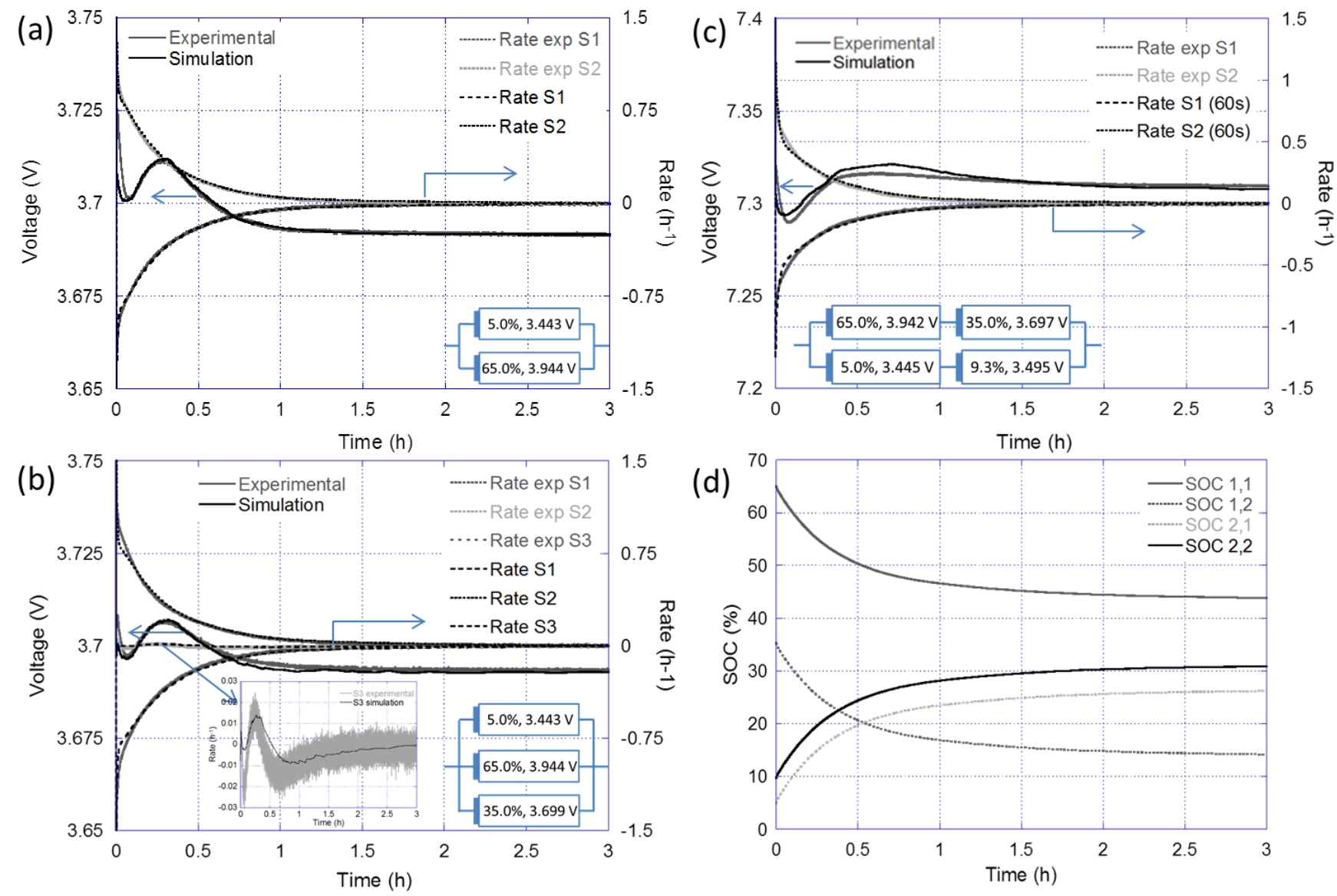

Figure 5: (a) Comparison of simulated and experimental cell voltage $v s$. time profiles generated from a 1S2P, (b) a similar comparison with cell voltage $v$ s. time profiles from a 1S3P configuration; (c) A 2S2P simulation vs. experimental voltage and current profiles, and (d) temporal SOC variations in SOCs among the cells.

Regarding the SOC variations in the cell balancing, the final SOC of the 1S2P assembly is $36.3 \%$. This final SOC is similar to the average of the starting SOCs, $36.2 \%$. A similar observation was made in the 1S3P assembly. This implies that, if cell-to-cell variations were small, the simplest way to calculate the final equilibrium voltage of an assembly after balancing is to calculate the OCV of the average value of the initial SOCs, not averaging the OCVs. This 
result may appear counterintuitive initially; but, strictly speaking, it is a thermodynamic result of balance in compositions, not potentials, as depicted by the non-linear correspondence of the ps$O C V=f(\mathrm{SOC})$ curve. It is not surprising that balancing two cells at, let say, $80.0 \%$ and $20.0 \%$ SOC should result in a final state at $50.0 \%$ SOC.

Figure 5(c) presents a $2 \mathrm{~S} 2 \mathrm{P}$ experiment with the comparison between the experimental and simulated voltage and current profiles for this experiment. Figure 5(d) shows the evolution of the individual SOCs simulated by the model. In the design of experiments, one of the strings comprises cells of $65.0 \%$ and $35.0 \%$ SOC and the others at $5.0 \%$ and around $10 \%(9.3 \%)$ SOC. The voltage and current variations follow the trends as observed in the previous experiments: the profiles from the simulation are sufficiently precise and accurate with small discrepancies in the first five minutes. The final SOCs determined from the model were consistent with SOCs derived from the $p s-O C V$ of the four cells in the assembly, as shown in Figure 5(d). At equilibrium, the cells exhibited 21.0\% SOC departure from their initial SOCs. The final SOC value is also consistent with the half of the difference of the initial SOCs between the two strings, i.e. $42.5 \%$; thus, each string accommodated $21.2 \%$ in the SOC variations.

\section{DISCUSSION}

\subsection{The kaulike approach}

In general, the simulation approach used in this work was very successful in predicting the evolutions of voltage and current profiles during the transient period of cell balancing in $(n \mathrm{~S} m \mathrm{P})$ parallel string configurations. The required computation resource is feasible with current portable PC platforms and rather small sets of experimental data from single cells are needed to construct the model. Even with the observed minor discrepancy in the initial period of balancing (in the first few minutes), the simplified ECM (a simplified Randles circuit) with an 
approximated capacitance value could emulate the dynamic balancing in parallel strings with sufficient precision and accuracy. In combination with EIS, this approach could result in improved precision in temporal resolutions with a better estimation of the capacitance in the model that is supposed to be related to charge transfer. This capacitance can affect the cell behavior in a range from $30 \mathrm{~s}$ to several hours [43].

The benefits of this approach could be expanded to practical applications, including acting as an estimator of the time required to balance a battery system, a tool to predict SOC variations in a battery pack with specific topology, a safety model to assess pack reliability versus cell failure modes and risk of overcharge or overdischarge in cells within the pack topology. It can also be used to assess the effect of cell-to-cell variations on system balancing and quality of the contacts on system reliability. Furthermore, it can be used to assess the effect of string swapping, at rest or hot. By extracting experimental data from the literature [17, 20, 21], we found that simulated curves by this ECM were in good agreement with the reported data. We are therefore confident that this simple approach has the validity for the above applications.

\subsection{Applications beyond laboratory}

Here a few examples with hypothetical scenarios that are difficult to test in laboratory setting are discussed to illustrate the utilities of this kaulike approach. As mentioned in [28], in order to facilitate durability, reliability and safety assessments of a battery system, it is desirable to have a tool to evaluate the tolerance needed to build into the battery system to withstand abuses, to aid the BMS managing abuse situations beyond the level of cell monitoring, and to allow the system handling possible failure modes (e.g. open or short circuit conditions), performing maintenance, and enabling string re-configurations (e.g. changing defective strings with new ones) in repairs. These scenarios involve testing on large assemblies that cannot be easily handled with laboratory experiments. 


\subsubsection{Scenarios with cell failure modes}

Here two critical failure modes, short circuit (SC) or open circuit (OC) [28], in parallel-string configurations were studied to evaluate a battery system's tolerance to abuse or failure. The first example is to assess the minimum number of cells in an assembly to handle SC or OC failures as a function of topology. The objective is to determine how many cells in the assembly can safely balance themselves in such failures and if the durability of the assembly would be impacted by the failures or possible imbalance. It should be noted that for traditional Li-ion batteries, prolonged SC could induce thermal runaway or separator shutdown and in turn lead to OC. However, a very short duration of SC may not trip thermal runaway. Additionally, Li-ion

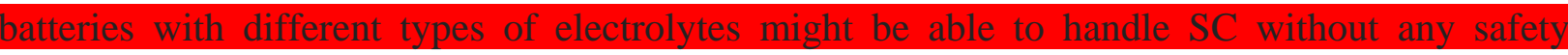

concerns.

The first case of the studies is using an assembly with a topology that has no cross wiring among strings in a scenario that one of the cells failed in short circuit. If a cell failed in SC, a crucial consideration on the abuse tolerance of the assembly would be if the remaining cells in the string could withstand the failure in the event. With one cell at SC, the other cells in the string need to accommodate the loss of voltage (e.g. as much as $4.100 \mathrm{~V}$ for a fully charged $\mathrm{Gr} \|$ $\{\mathrm{NMC}+\mathrm{LMO}\}$ cell) in the assembly. Figure 6(a) presents the result of a simple straight forward calculation of the impact of accommodating a $4.100 \mathrm{~V}$ voltage drop for an $n \mathrm{~S} m \mathrm{P}$ assembly set to cut off at $n \times 4.100 \mathrm{~V}, n \times 4.200 \mathrm{~V}$, and $n \times 4.250 \mathrm{~V}$, respectively, during charging with safety limits set at $4.200 \mathrm{~V}$ or $4.250 \mathrm{~V}$ per cell. This calculation assumes that the non-shorted $n$ - 1 cells need to stand up for the same voltage as $n$ cells in the normal strings. If these non-shorted $n-1$ cells are charged to $4.100 \mathrm{~V}$, a total of 29 cells in the string would be necessary for the assembly to remain operative if the safety limit is set at $4.250 \mathrm{~V}$. If the safety limit were set at $4.200 \mathrm{~V}$, 
this number increases to at least 42 cells. For cutoff voltages above $4.100 \mathrm{~V}$, more cells would be needed in the string to accommodate the SC failure.

(a)

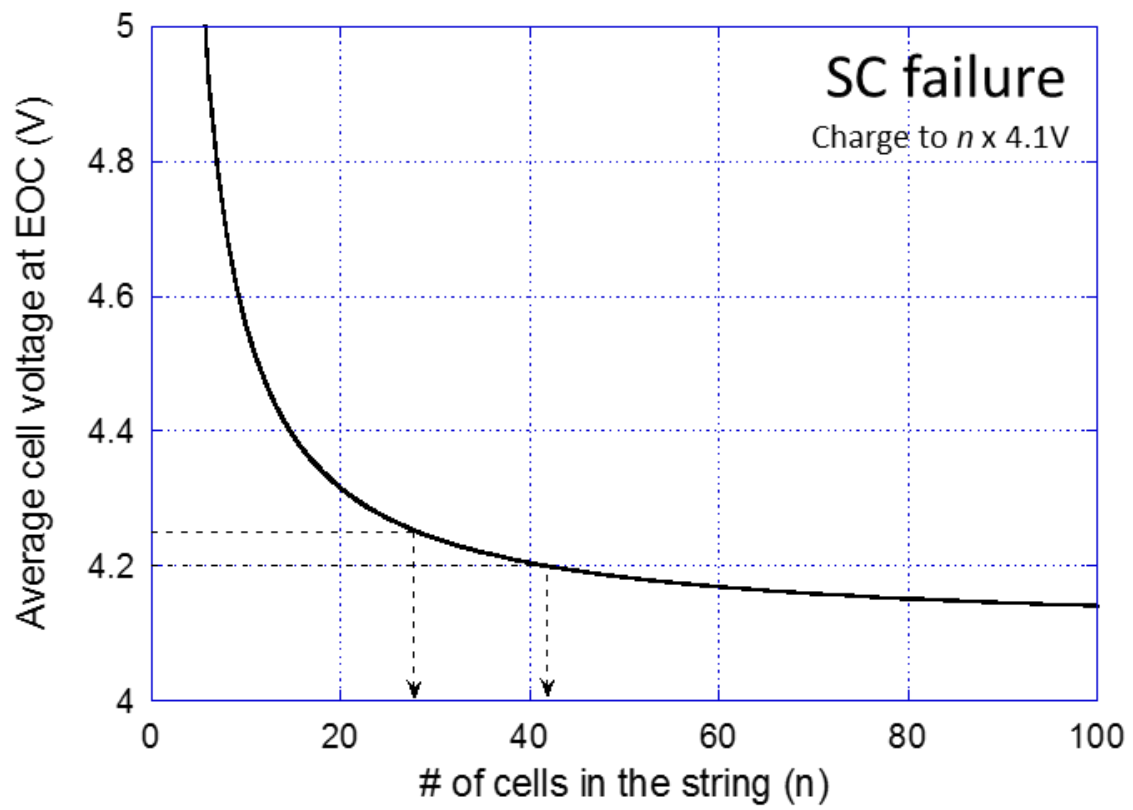

(b)

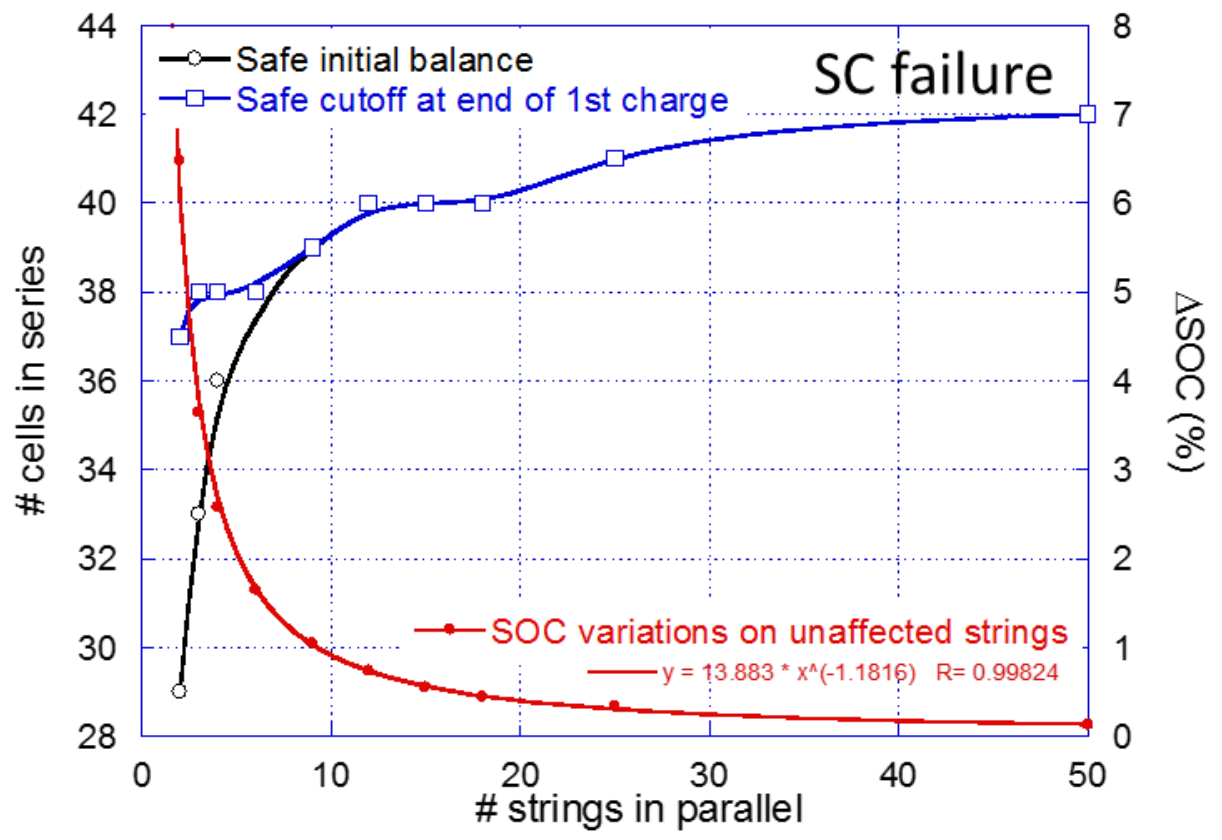

Figure 6: (a) A simple calculation of the effect of a SC failure in an assembly and (b) the results of simulations using the kaulike approach. 
To validate the results of this simple illustration, the kaulike model was used to conduct simulation of current distributions among the strings and assess the tolerance of the assembly in the balancing. This tolerance was evaluated with two criteria: whether or not the assembly could balance itself right after the failure and whether or not the assembly could safely resume normal operation. The latter was validated if the assembly could perform a full cycle after the failure. The assembly should fail the test if any of the steps triggered a safety event during the simulation.

Starting from a fully charged and balanced state in the assembly, the following steps were used in the simulation:

- A six-hour idling period to allow the assembly reacting to the single-cell SC failure.

- A full discharge using constant power mode at a nominal power rating $(\mathrm{P} / 1$ discharge, the constant power level to discharge the cell in one hour) to the voltage cutoff condition $(n \times$ $3.000 \mathrm{~V})$.

- A charge regime starting with $\mathrm{C} / 2$ rate until the string reached $(n \times 4.100 \mathrm{~V})$ followed by $\mathrm{C} / 25$ to the same cutoff. The $\mathrm{C} / 25$ charge was conducted to ensure full recharge could be attained to supplement the $\mathrm{CV}$ step that is commonly used in a typical charge regime, which cannot be handled by the ECM in this approach.

- A six-hour rest to allow the assembly to equilibrate.

- A second discharge regime at $\mathrm{P} / 1$ rate to evaluate the capacity released by the assembly after the recharge.

In this study, the cutoff conditions were set at $n \times 4.100 \mathrm{~V}$ in the charge regime and $n \times 3.000 \mathrm{~V}$ in the discharge, where $n$ is the number of cells in the string (including the SC cell). The safety limits were set at $4.200 \mathrm{~V}$ and $2.800 \mathrm{~V}$ per cell in the charge and discharge regime, respectively. One of the worst scenarios considered is the one starting with strings of fully charged cells at 
$4.100 \mathrm{~V}$, because at this state the assembly has little room to alleviate triggering safety events. From the simulation of this scenario, the minimum number of cells in the string to handle other severe scenarios can be derived.

Simulations using the kaulike model were performed for the case of $n \times 4.100 \mathrm{~V}$ charge cutoff with a $4.200 \mathrm{~V}$-per-cell safety limit. Under these conditions and according to Figure 6(a), 42 cells would be necessary to operate the assembly with sufficient safety margin to permit one cell suffering SC failure. Simulation results, shown in Figure 6(b), indicate that the minimum number of cells required is actually lower when the number of strings in parallel is small (but higher than 1). For instance, a 29S2P assembly should be able to endure a single-cell SC failure, but it could not be recharged (i.e. allow the assembly to complete a charge regime to $n \times 4.100 \mathrm{~V}$ without triggering the $4.200 \mathrm{~V}$ safety limit). However, a 37S2P assembly is sufficient to recharge safely in the same scenario. The number of cells in the string is increased to 39 to safely operate in the above scenario with a 9P assembly; and analogously, 42 cells, the number predicted in Figure 6(a), are required if more than 50 strings in parallel are assembled.

The discrepancy in the number of cells predicted by the two methods is due to the fact that the simple calculation in Figure 6(a) assumes that the voltage of the normal strings is rather constant during the balancing in the failure mode. This assumption neglects the effect of the balancing current on the normal strings, which diminishes with an increasing number of strings. If the balancing current passing through the normal strings is not negligible, the (assembly) voltage should not stay constant but decrease. To elaborate on this aspect, an additional scale on the left of Figure 6(b) was provided to indicate the SOC variations in the strings. If only two strings were in parallel, the SOC variations would be about $9.0 \%$ per string (i.e. from $91.0 \%$ to $100.0 \%$ in the string with a single-cell SC failure and from $91.0 \%$ to $82.0 \%$ for the other). The 
more strings in parallel, the less are the SOC variations per string and the number of cells in series to withhold a SC failure as shown in Figure 6(a).

The previous paragraph focused on the safety aspect of the balancing. Next, the durability of the assembly should be assessed, especially the impacts on capacity under the single-cell SC failure. The results from the ECM simulation indicate that the discharge duration at $\mathrm{P} / 1$ of an assembly with single-cell SC failure could last more than $98 \%$ of that of a normal assembly. Moreover, the mean current through the strings was only marginally affected by the single-cell SC failure; thus, the capacity loss would be minimal.

The second scenario here is to investigate the impact of single-cell OC failure in an assembly with a common parallel-string connection (i.e. no cell-to-cell cross contacts among the adjacent strings). In the OC failure mode, the key concern is not the number of cells in the strings but the number of strings in the assembly, since a single-cell OC failure shall disable the entire string. Here, the voltage of the string is not a concern either, but the current passing through the active strings is. Figure 7 presents the simulated results from the ECM for various situations with single-cell OC failure mode. The scale on the left is the rate multiplication value per active string versus the number of strings in parallel. The rate multiplication value represents the enhancement in the discharging rate in each active string as a function of the number of strings in parallel upon the single-cell OC failure, as denoted by the solid black curve. The scale on the right shows the relative discharge duration at $\mathrm{P} / 1$ and $2 \mathrm{P}$, as represented by the dashed lines respectively, as a function of the number of strings in parallel upon the single-cell OC failure. Here, the string-to-string variations were not considered. Concerning the severity of the impact from the single-cell OC failure, it is the worst for two strings in parallel; but the impact rapidly diminishes to below 1.2 when six or more strings are in parallel. Although this cell design is not for high power, the $\mathrm{P} / 1$ discharge duration for assemblies with less than six strings in parallel can 
still last more than $80 \%$ of its time in service. At the $2 \mathrm{P}$ rate, the time in service, and likely the capacity, would be drastically affected by the single-cell OC failure in a string, and more than 12 strings in parallel would be needed to maintain more than $80 \%$ of the discharge duration by the assembly to endure such a failure.

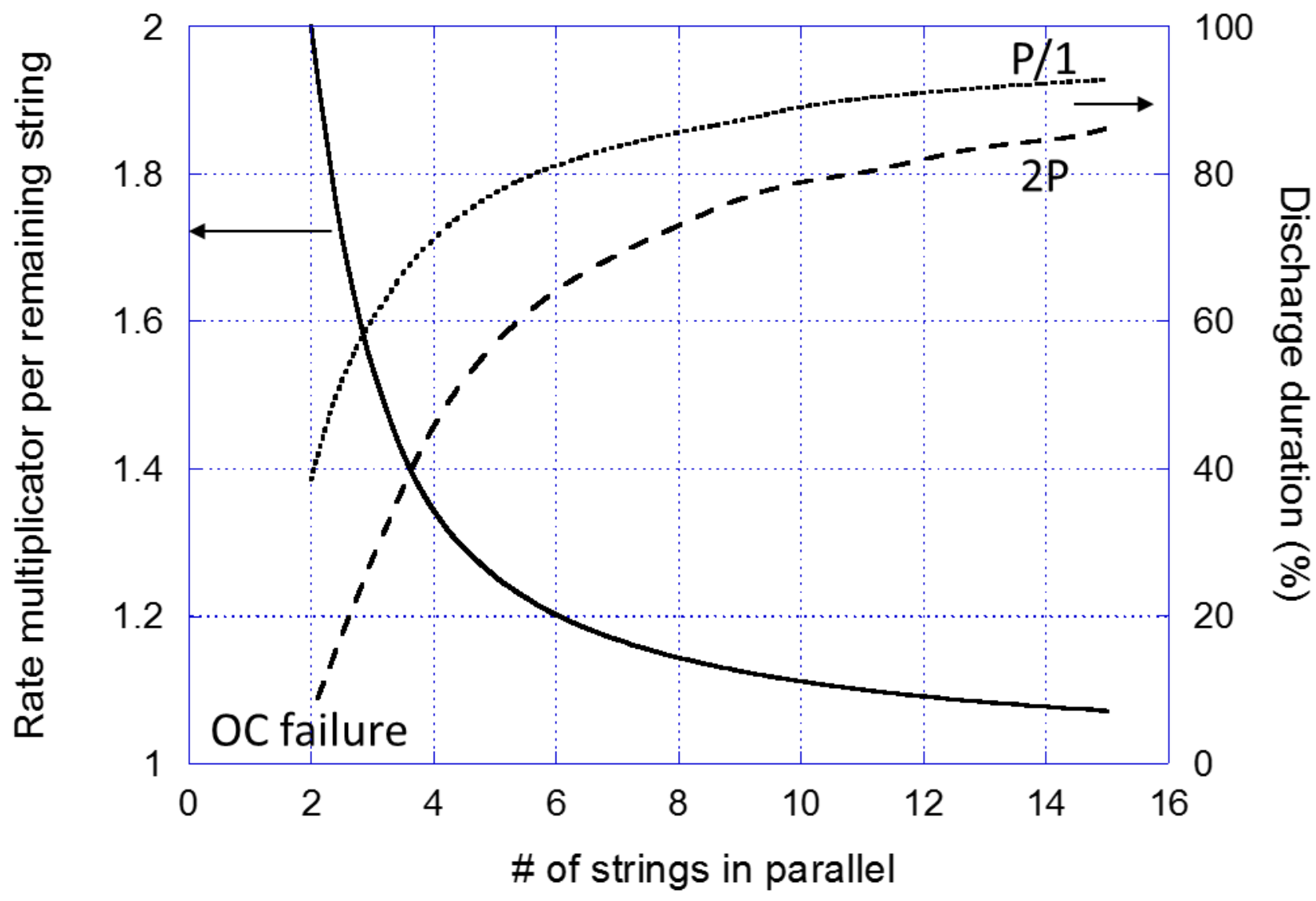

Figure 7: Effect of an OC failure on the rate passing though the remaining strings and on the capacity of the assembly under $\mathrm{P} / 1$ and $2 \mathrm{P}$ discharges.

In light of the above analyses, in terms of battery abuse tolerance, safety and durability, it appears that size and topology of the battery system matter. In small to medium size assemblies, say those having less than 37 to 42 cells in series, short circuit failure could create substantial risk, and these systems have not enough margin to weather the failure at high voltage situations. 
With insufficient number of cells, the single-cell SC failure could tip the balance in the assembly and force undesirable overcharge on those cells in the failed string, even during idling or rest period. Only physically disconnecting the failed string from the assembly could prevent the risk of overcharging and possible thermal runaway.

In an OC failure, the assembly should remain functional for all parallel configurations, since no string-to-string balancing involved. However, the OC failure does affect the performance in a progressive manner more critical for smaller numbers of strings in parallel, including service time and capacity, especially with high-energy designs.

For cross-wired configurations, where cell-to-cell contacts are present among parallel strings, the OC or SC failures could still have effects on the assemblies similar to the non-cross-wired configurations. A cross-wired configuration might be seen as a combination of a $1 \mathrm{~S} m \mathrm{P}$ system, where each module in series is composed of $m$ parallel cells; and an $n \mathrm{S1P}$ system, where each module in parallel is composed of $n$ cells in series. In a SC failure, the cross-wired system could be viewed as an $n \mathrm{~S} 1 \mathrm{P}$ system: since the $\mathrm{SC}$ failure shall completely disable the affected (1SmP) module and the current shall flow through the less resistive path of short circuit. Therefore, the assembly is equivalent to an (n-1)S1P system but operated as an $n \mathrm{~S} 1 \mathrm{P}$ system. This scenario implies that a high number of cells, at least 42 of Gr $\|$ NMC cells in series, are necessary for the assembly to remain useable. Analogously, in an OC failure, it is necessary to view the assembly as a $1 \mathrm{~S} m \mathrm{P}$ system. The $\mathrm{OC}$ failure shall increase the rate on all the other cells of the $(1 \mathrm{~S} m \mathrm{P})$ module besides the OC one and thus reduce the usable capacity of this module and the assembly. This module is also likely to degrade faster which would likely induce some rising imbalance issues that could lower the assembly capacity even more [7]. 


\subsubsection{Scenarios with string swapping}

String swapping could happen frequently in maintenance and repair, when in an aged system a dysfunctional or incompatible string needs to be replaced. No well-established approach avails to address the compatibility issue for string swapping to date. In order to demonstrate the utility of this kaulike approach for string swapping, we shall use the RPT data from a previous study [3] to build an "aged cell" ECM and simulate a series of $12 \mathrm{~S} 6 \mathrm{P}$ assemblies with aged cells in various states of degradation and simulate the effects with a new string swapped. This exercise could allow us assessing any potential issues or hazards with string swapping and maybe its benefits.

The "aged cell" model and simulation results were based on a cell that has been cycled 250 and 500 cycles at $2 \mathrm{C}$ and room temperature [3]. The capacity losses were $6.3 \%$ and $12.5 \%$ at 250 and 500 cycles, respectively, with resistance increases at $10 \%$ and $20 \%$. The capacity loss was inferred to be largely originated from loss of lithium inventory [3]. Since we are interested in knowing if the assembly could balance itself after the swap and if the assembly would be safe to resume normal operation after the swap, simulations were carried out using the same protocol as in the SC simulation, in which cutoffs and safety limits remained as proposed. Three sets of simulation were performed, and the results were compared to those of the initial response of the assembly. In the first set, all cells were presumably aged and degraded equally to a state equivalent to that of the sample cell after cycle aged for 250 cycles at $2 \mathrm{C}$. In the second set, the same presumption was made except one cell, which was degraded to a state equivalent to that of the cell cycle aged for 500 cycles at $2 \mathrm{C}$. In the third set, the string with the most degraded cell was replaced by a brand-new one. The swapping was simulated at a fully charged state with all cells in the strings at $4.100 \mathrm{~V}$. 
Figure 8 (a) presents the percentage of $\mathrm{P} / 1$ discharge duration (i.e. service time) for the three sets of simulation compared to the initial value of a new string. In the first set of simulation, after 250 cycles the assembly lost about $11 \%$ of service time. If one cell in a string degraded more as specified in the second set of simulation, $12 \%$ of service time was lost. Replacing the string that contains more severely aged cell by a brand-new one only improves the service time by $3 \%$ (i.e. the assembly still exhibits $9 \%$ loss).

Figure 8 (b) presents the temporal variation of the $12 \mathrm{~S} 6 \mathrm{P}$ assembly voltage and rate (current) under a P/1 discharge before (in the second set) and after the string swap (in the third set). Since the resistance of the new string is lower, the assembly voltage in the third set of simulation after the string replacement is consistently higher than that of the second set. The mean discharge rate per string was lowered after the swap by about $2 \%$ to $1.05 \mathrm{C}$ instead of $1.07 \mathrm{C}$. For the first half of the discharge regime $(<0.4 \mathrm{~h})$, the rate on the newly replaced string was rather constant at about $1.18 \mathrm{C}$, then it increased to more than $1.30 \mathrm{C}$ at $0.6 \mathrm{~h}$ before rapidly decreasing to $0.80 \mathrm{C}$ at the end of discharge. This pattern of behavior could be explained by the differences in the string voltages between the replaced string and those aged strings (i.e. acting as driving force for string balance), which is a function of SOC. In the high voltage region, where SOC is high, the lower impedance of the newly replaced string dominated the current distribution in the assembly; thus, this string should endure a consistently higher rate at $1.18 \mathrm{C}$. After $0.40 \mathrm{~h}$, due to the increasingly higher voltage difference and lower impedance, the replaced string should endure an even higher rate than those of the other strings. When the discharge regime was close to the end, the replaced string should experience an earlier depletion of capacity ahead of other strings in the assembly due to a continuously higher rate of discharge. Finally, a reversal of the impedance allowed the other strings to catch up in the discharge regime, while the replaced string exhibited a drastically diminishing current toward the end of discharge. 
These simulation results suggest that the string swapping can be conducted safely, but the replacement of a new string would not recover most of the lost capacity in the assembly. The lifespan of the assembly (durability) may be extended once the damaged cell was successfully removed from the assembly.

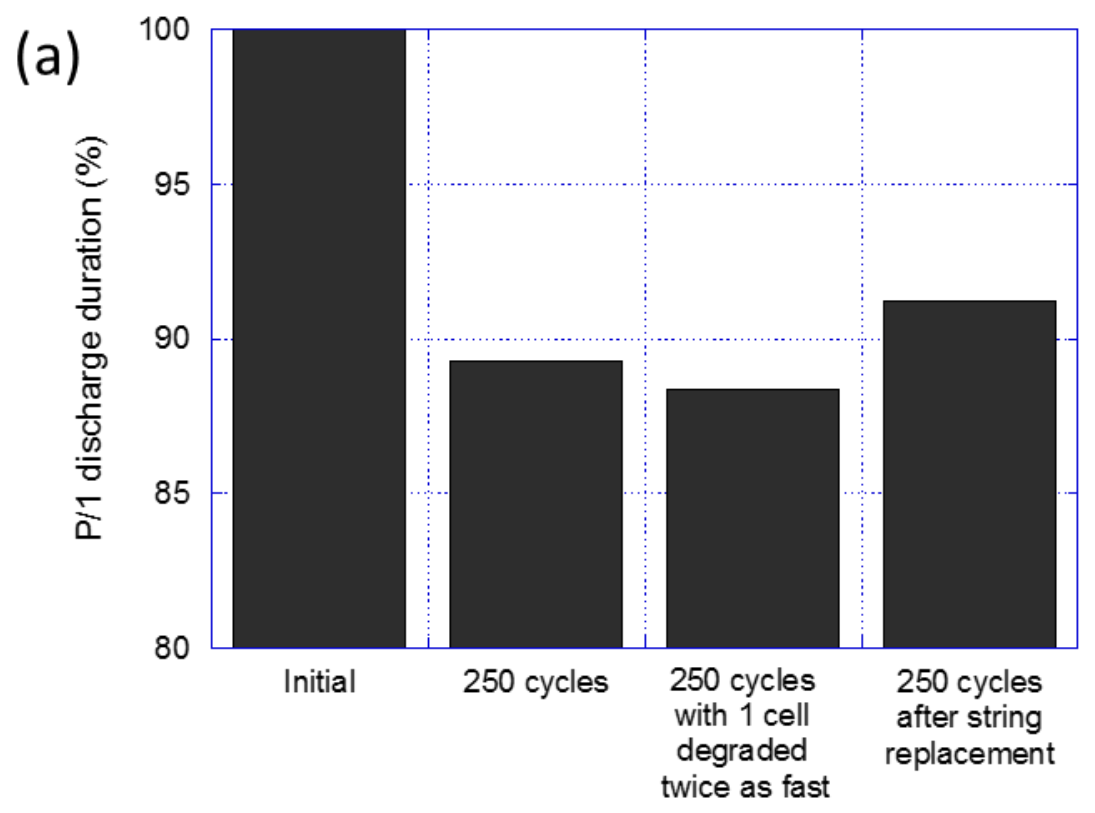

(b)

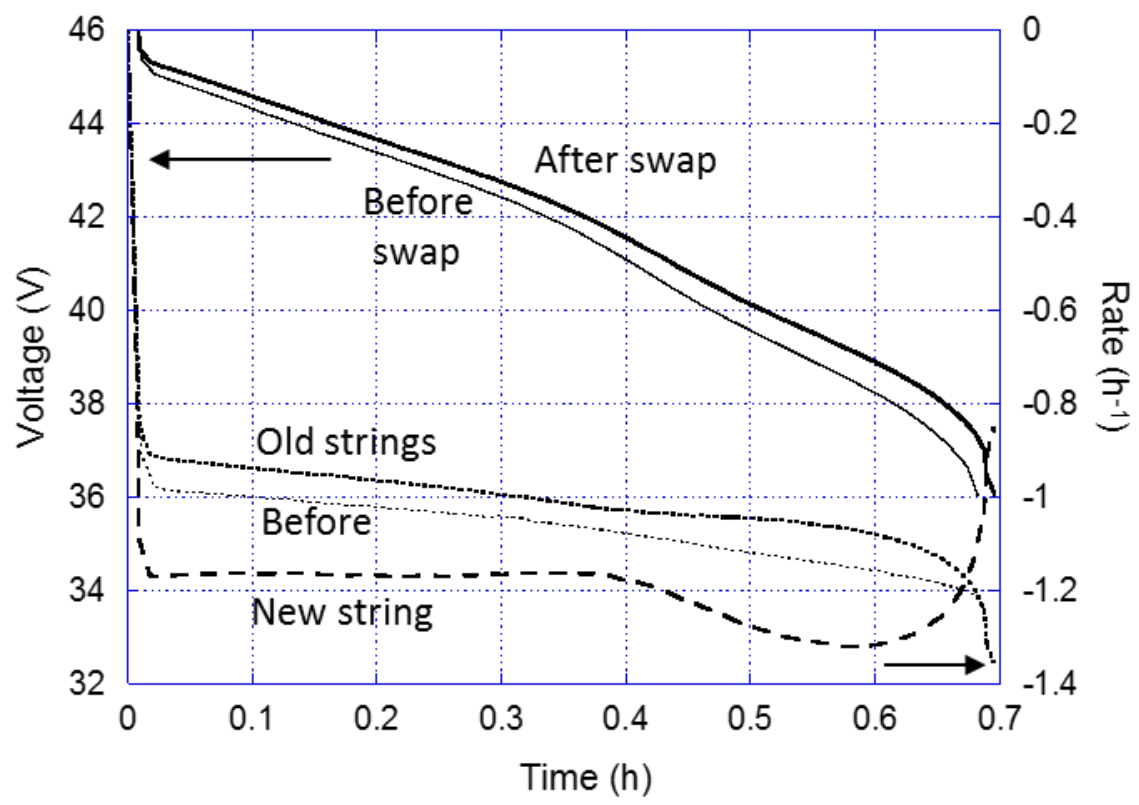

Figure 8: (a) P/1 discharge time of a new assembly, an assembly after $2502 \mathrm{C}$ cycles, an assembly after $2502 \mathrm{C}$ cycles with one cell that degraded twice as fast, and an assembly with one 
aged string swapped for a new one. (b) Comparison of the P/1 discharge voltage and rate evolution before and after string replacement.

\section{CONCLUSION}

A precise and accurate equivalent circuit model using the kaulike approach to simulate the electrochemical behavior of cells or strings in parallel configurations is illustrated here. The approach is based on a simplified ECM that can be used to determine the intersection of $V_{\text {string }}=$ $f($ rate $)$ curves for the strings in an assembly and thus derive the transient balancing current and the steady voltage of the assembly at the end of the balance. Using cells at different SOCs connected in parallel in 1S2P, 1S3P and 2S2P configurations, this approach was verified feasible as validated with experimental data. It was further proved that this approach is useful to assess the impacts of cell failures in open or short circuit conditions with a variety of different assembly configurations. Further attempts were exercised to illustrate the potential of this approach in practical use, such as simulating the impacts of string swapping in aged assemblies. This kaulike approach and the equivalent circuit model simulation could be very useful for prognosis of large battery energy storage systems with a large number of cells or modules in parallel configurations that could be subjected to cell or module failures, asymmetric degradation among cells, modules and strings, and replacement of cells, modules or strings in maintenance or repair. This approach could be a key diagnostic and prognostic method to address system level durability, reliability and safety issues. 


\section{ACKNOWLEDGEMENTS}

The authors are grateful to the funding provided by the Office of Energy Efficiency and Renewable Energy of the United States Department of Energy (Contract No. DE-AC0705ID14517).

\section{REFERENCES}

[1] K.L. Gering, S.V. Sazhin, D.K. Jamison, C.J. Michelbacher, B.Y. Liaw, M. Dubarry, M. Cugnet, J. Power Sources, 196(7) (2011) 3395-3403.

[2] M. Dubarry, C. Truchot, M. Cugnet, B.Y. Liaw, K. Gering, S. Sazhin, D. Jamison, C. Michelbacher, J. Power Sources, 196(23) (2011) 10328-10335.

[3] M. Dubarry, C. Truchot, B.Y. Liaw, K. Gering, S. Sazhin, D. Jamison, C. Michelbacher, J. Power Sources, 196(23) (2011) 10336-10343.

[4] M. Dubarry, C. Truchot, B.Y. Liaw, K. Gering, S. Sazhin, D. Jamison, C. Michelbacher, J. Electrochem. Soc., 160(1) (2013) A191-A199.

[5] M. Dubarry, C. Truchot, A. Devie, B.Y. Liaw, K. Gering, S. Sazhin, D. Jamison, C. Michelbacher, J. Electrochem. Soc., 162(9) (2015) A1787-A1792.

[6] C. Truchot, M. Dubarry, B.Y. Liaw, Appl. Energy, 119(2014) 218-227.

[7] M. Dubarry, C. Truchot, A. Devie, B.Y. Liaw, J. Electrochem. Soc., 162(6) (2015) A877A884.

[8] N. Kutkut, L.N. Wiegman, D.M. Divan, D.W. Novotny, Industry Applications, IEEE Transactions on, 35(1) (1999) 28-35.

[9] C. Bonfiglio, W. Roessler, in: Vehicle Power and Propulsion Conference, Dearborn, MI, USA, 2009, pp. 304-309.

[10] T. Kim, Q. Wei, L. Qu, IEEE, (2011) 3459-3555.

[11] S.P. Hsu, C.L. Lin, J.Y. Wu, in: Industrial Electronics and Applications (ICIEA), 2012 7th IEEE Conference o, Singapore, 2012, pp. 613-618.

[12] D.D. Quinn, T.T. Hartley, J. Power Sources, 240(2013) 26-32.

[13] J. Gallardo-Lozano, E. Romero-Cadaval, M.I. Milanes-Montero, M.A. Guerrero-Martinez, J. Power Sources, 246(2014) 934-949.

[14] M. Fleckenstein, O. Bohlen, M.A. Roscher, B. Bäker, J. Power Sources, 196(10) (2011) 4769-4778.

[15] G. Zhang, C.E. Shaffer, C.Y. Wang, C.D. Rahn, J. Electrochem. Soc., 160(4) (2013) A610A615.

[16] T. Tsujikawa, K. Yabuta, M. Arakawa, K. Hayashi, J. Power Sources, (2013).

[17] S. Miyatake, Y. Susuki, T. Hikihara, S. Itoh, K. Tanaka, J. Power Sources, 241(2013) 736743.

[18] J. Kim, B.H. Cho, Energy, 57(2013) 581-599.

[19] G.J. Offer, V. Yufit, D.A. Howey, B. Wu, N.P. Brandon, J. Power Sources, 206(2012) 383392.

[20] J. Zhang, S. Ci, H. Sharif, M. Alahmad, IEEE Transaction on Energy Conversion, 25(4) (2010) 1133-1141. 
[21] M.-S. Wu, C.-Y. Lin, Y.-Y. Wang, C.-C. Wan, C.R. Yang, Electrochim. Acta, 52(3) (2006) 1349-1357.

[22] Y. Zhang, J. Jiang, W. Zhang, W. Shi, Z.F. Ma, F. Zheng, Lecture Notes in Electrical Engineering 288(2014) 95-104.

[23] G. Zhang, C.E. Shaffer, C.Y. Wang, C.D. Rahn, J. Electrochem. Soc., 160(11) (2013) A2299-A2305.

[24] D. Shin, M. Poncino, E. Macii, N. Chang, IEEE Transactions on Computer-Aided Design of Integrated Circuits and Systems, 34(2) (2015) 252-265.

[25] S. Kamalisiahroudi, J. Huang, Z. Li, J. Zhang, International Journal of Electrical, Robotics, Electronics and Communications Engineering, 8(10) (2014) 1399-1402.

[26] R. Gogoana, M.B. Pinson, M.Z. Bazant, S.E. Sarma, J. Power Sources, 252(2014) 8-13.

[27] F. Baronti, R. Di Rienzo, N. Papazafiropulos, R. Roncella, R. Saletti, in: IEVC2014, Florence, I, 2014, pp. 1-7.

[28] J. McDowall, Parallel and Series Connections, in: D. Rand, B. Scrosati (Eds.) Encyclopedia of Electrochemical Power Sources, Elsevier, Amsterdam, 2009, pp. 499-509.

[29] M. Dubarry, N. Vuillaume, B.Y. Liaw, Int J Energ Res, 34(2) (2010) 216-231.

[30] S. Santhanagopalan, R.E. White, International Journal of Electrochemistry, 2012(2012) 1

[31] B. Kenney, K. Darcovich, D.D. MacNeil, I.J. Davidson, J. Power Sources, 213(2012) 391401.

[32] M. Dubarry, N. Vuillaume, B.Y. Liaw, J. Power Sources, 186(2) (2009) 500-507.

[33] M. Dubarry, B.Y. Liaw, J. Power Sources, 174(2) (2007) 856-860.

[34] http://www.arbin.com/index.php/store/battery-holders/high-current-cylindrical-batteryholder-detail, last accessed 01/27/2016.

[35] http://www.flex-core.com/hall-effect-dc-current-transducer-model-cth, last accessed $01 / 27 / 2016$.

[36] M. Dubarry, C. Truchot, B.Y. Liaw, J. Power Sources, 219(2012) 204-216.

[37] M.W. Verbrugge, R.S. Conell, J. Electrochem. Soc., 149(1) (2002) A45.

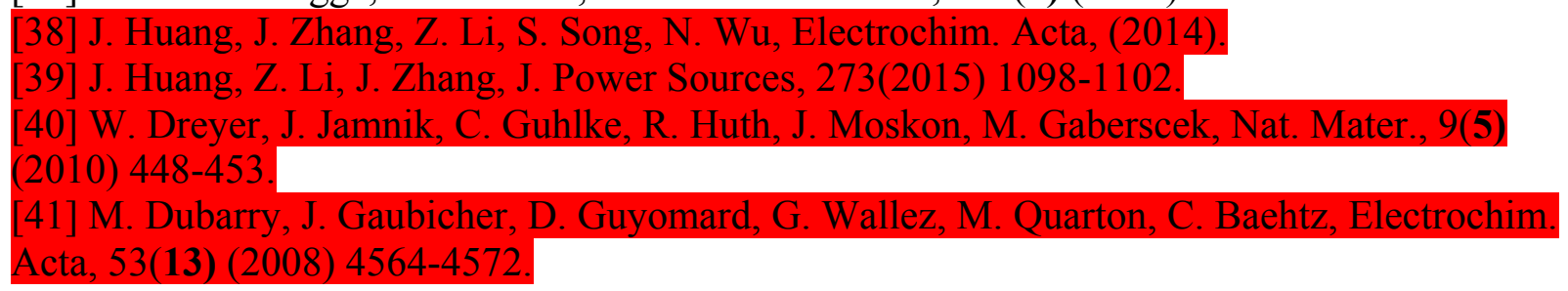

[42] M. Dubarry, N. Vuillaume, B.Y. Liaw, in: 17th IEEE International Conference on Control Applications, San Antonio TX, 2008, pp. 708-713.

[43] A. Jossen, J. Power Sources, 154(2) (2006) 530-538. 


\section{FIGURE CAPTIONS}

Figure 1: Cell voltage $v s$. SOC curves determined by experiments for a nominal cell and a schematic illustration of a hypothetical $1 \mathrm{~S} 2 \mathrm{P}$ configuration in which how the rate of the balancing current and the final voltage of the assembly determined for the two cells at $91.0 \%$ and $1.3 \%$ SOC (4.100 V vs. $3.200 \mathrm{~V})$, respectively, initially before being connected in parallel.

Figure 2: Schematic illustrating the ECM approach used in this work and how parameters and the $V_{\text {cell }}=f(\mathrm{SOC})$ curves at different rates were derived.

Figure 3: Schematic illustrating the application of (a) $V_{\text {cell }}=f(\mathrm{SOC})$ curves in the determination (b) of the single cells polarization curves and (c) of the rate of the balancing current and the final voltage of the cell assembly in the $1 \mathrm{~S} 2 \mathrm{P}$ configuration.

Figure 4: An illustration of the determination of the rate of balancing current and the final voltage of the assembly in (a) an $n \mathrm{~S} 2 \mathrm{P}$ configuration and (b) for an $n \mathrm{~S} 2 \mathrm{P}$ configuration (dotted box) and an $n \mathrm{~S} m \mathrm{P}$ configuration.

Figure 5: (a) Comparison of simulated and experimental cell voltage $v s$. time profiles generated from a 1S2P, (b) a similar comparison with cell voltage $v s$. time profiles from a 1S3P configuration; (c) A 2S2P simulation vs. experimental voltage and current profiles, and (d) temporal SOC variations in SOCs among the cells.

Figure 6: (a) A simple calculation of the effect of a SC failure in an assembly and (b) the results of simulations using the kaulike approach.

Figure 7: Effect of an OC failure on the rate passing though the remaining strings and on the capacity of the assembly under P/1 and 2P discharges.

Figure 8: (a) P/1 discharge time of a new assembly, an assembly after $2502 \mathrm{C}$ cycles, an assembly after $2502 \mathrm{C}$ cycles with one cell that degraded twice as fast, and an assembly 
with one aged string swapped for a new one. (b) Comparison of the P/1 discharge voltage and rate evolution before and after string replacement. 


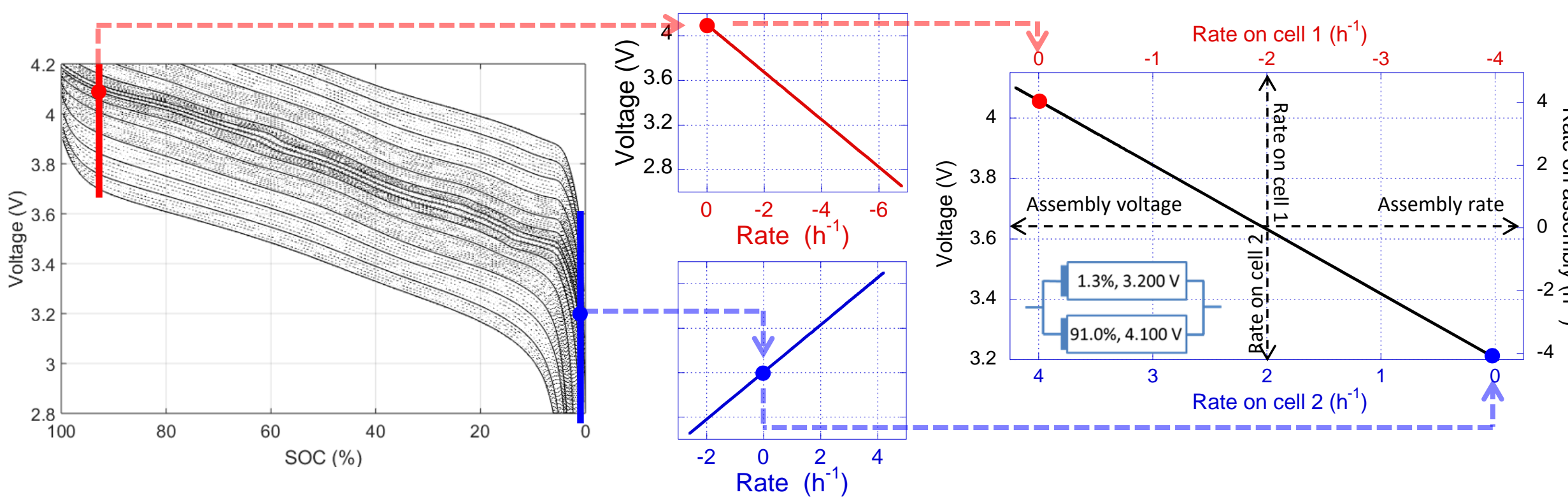

